\title{
The Challenge of Fenestrated Atrial Septal Defects closure; which device to choose?
}

\author{
Mohammed T Numan ${ }^{1,2 *}$, Howaida El-Said ${ }^{1,2}$, Muhammed Dilawar ${ }^{1,2}$ and Amal El Sisi ${ }^{1,2}$ \\ ${ }^{1}$ University of Texas, Houston, Rady Children's Hospital, San Diego, USA \\ ${ }^{2}$ University of Cairo, Hamad Hospital, Doha-Qatar, Egypt
}

\begin{abstract}
Introduction: Multiple atrial defects and interatrial aneurysm with fenestrations are still limitation to any device closure and are associated with higher incidence of complications. We previously reported the feasibility of closing multiple fenestration ASDs with and without aneurysm using the Cribriform Amplatzer and the Helex devices. In this study we are comparing these two different brands of special devices in closing the multifenestrated ASDs, looking at technical aspects, procedure duration, residual shunt and short- and long-term complications.
\end{abstract}

Methods: Between August 2003 and December 2007, thirty-eight patients were diagnosed as having fenestrated ASDs with and without septal aneurysm by transthoracic echocardiography (TTE). They were scheduled for Cribriform or Helex device closure. The choice of the device was operator preference. Attempted implantation with Cribriform device was done in Eighteen patients (group A) versus twenty patients had the newly modified Helex device (group B). There was no significant statistical difference between group A and B in age, weight, sex and Qp:Qs.

Results: Procedure was done under general anesthesia with simultaneous transesophageal echocardiography (TEE) performed in 32 patients or under sedation with intracardiac echocardiography (ICE) in 6 patients. Successful implantation was 15/18 in group A and 19/20 in group B.

\begin{tabular}{|c|c|c|c|}
\hline & Group A & Group B & p value \\
\hline PFO (Number/total) & $7 / 20$ & $0.02^{*}$ & $25 \mathrm{~mm}$ \\
\hline Mean device Size & $30 \mathrm{~mm}$ & $1.7 / 1 \pm 0.7$ \\
\hline Qp/Qs (mean \pm SD) & $1.47 / 1 \pm 0.3$ & $92 \pm 63 \mathrm{~min}$ \\
\hline Procedure time & $68.7 \pm 29.5 \mathrm{~min}$ & $21 \pm 9.7 \mathrm{~min}$ \\
\hline Fluoro time & $10.8 \pm 5.3 \mathrm{~min}$ & $1 / 24(12 \%)$ \\
\hline Failed implantation & $2 / 20(10 \%)$ & $3 / 24(\%)$ \\
\hline Next day leak (\%) & $5 / 20(25 \%)$ & 0.15 \\
\hline Last FU leak (\%) & $2 / 18(11 \%)$ & 0.06 \\
\hline
\end{tabular}

Conclusion: Both devices were safe with low complications. Helex devices tend to take longer procedural and flouro times but have higher success implantation and less residual leak in short and long follow up.

\section{Introduction}

Transcatheter closure of single secundum atrial septal defect (ASD) has become an alternative to surgery, and the results have been mostly satisfactory. Multiple defects and interatrial aneurysm with fenestrations are still potential limitations to any device closure and are associated with a higher incidence of complications. An atrial septal aneurysm is a localized outpouching deformation of the fossa ovalis region of the interatrial septum that bulges into the right or left atrium, or both. Its rate of detection in living persons has increased since the advent of advanced diagnostic methods. Transthoracic echocardiographic studies estimated a prevalence between $0.08 \%$ and $1.2 \%$. More recent studies using transesophageal echocardiography have shown a prevalence between $2 \%$ and $10 \%$ [1]. Several studies suggest a possible relationship between atrial septal aneurysm and cerebrovascular events of embolic origin including stroke, transient ischemic attack (TIA), and systemic embolism Fenestrated ASDs with and without aneurysm may need several devices placed across the atrial septum which is more challenging, problematic and expensive $[2,3]$. Balloon atrial septostomy has been used to convert multiple defects into single defect to close with single device. We report the feasibility of closing multiple fenestration ASDs with and without aneurysm using the Cribriform Amplatzer and the HELEX devices. In this study we are comparing these two different brands of special devices in closing the multifenestrated ASDs, looking at technical aspects, procedure duration, residual shunt and short- and long-term complications. (Figure 1).

\section{Methods}

This is a retrospective study that includes all patients with fenestrated ASDs who were scheduled for catheter closure between August 2003 and December 2007 in Hamad hospital and University of Cairo. Forty-four patients were diagnosed as having fenestrated ASDs with and without septal aneurysm by transthoracic echocardiography

${ }^{*}$ Correspondence to: Mohammed T Numan, University of Texas, Houston, Rady Children's Hospital, San Diego, USA, E-mail: Mohammed.T.Numan@uth.tmc.edu

Received: October 01, 2018; Accepted: October 16, 2018; Published: October 19, 2018 

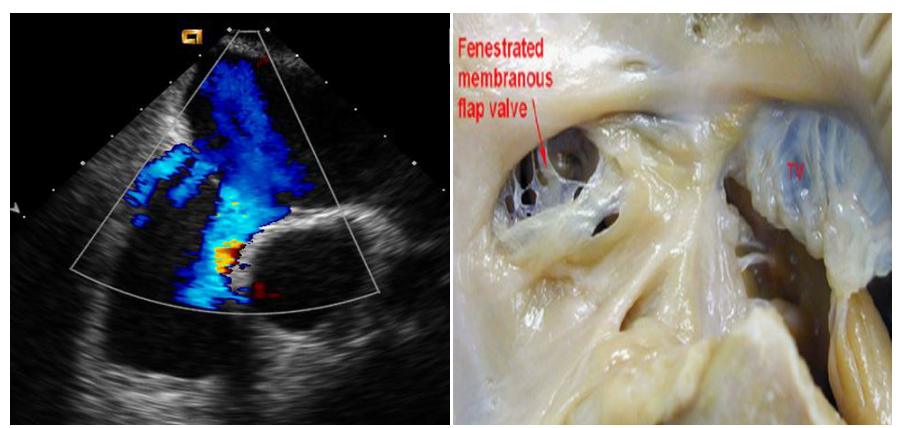

Figure 1. Echocardiogram representation of an anatomic specimen

(TTE). They were scheduled for device closure using either the AGA Amplatzer Cribriform or the GORE HELEX Septal Occluder. HELEX device was introduced in our institute in December 2005. The choice of the device was operator preference. Informed consent was obtained from patients or parents. Chest radiography, ECG and TTE were performed routinely prior to the procedure. (Figures 2-5).

\section{Device implantation procedure}

Procedure was done under general anesthesia with simultaneous transesophageal echocardiography (TEE) performed in 36 patients or under sedation with intracardiac echocardiography (ICE) in 8 patients. The TEE or ICE was used to assess defects diameter, intradefect distance, rims of superior, inferior and anterior atrial septum (AS), steady rim, total atrial septal length and the presence or absence of aneurysm as we reported previously. Those who had ICE were older patients. For ICE guided atrial septal defect device closure we used the methodology previously described by Earing and his colleagues [4].

Our methodology for assessing the defect size and subsequently making a determination for device selection whether Cribriform or Helex is previously published by our group [5]. This method of device size selection ensured that the device will cover all defects and not exceed the total septal length. It also ensured that the selected device should cover the whole base of atrial septal aneurysm if present.

Invasive blood pressure was continuously monitored throughout the procedure. Hemodynamic measurements including pulmonary artery pressure, pulmonary vascular resistance (PVR) and shunt calculation were performed prior to device implantation. The procedure was carried out if PVR was less than 4 Woods units. During the procedure all patients received 75 units per Kg Heparin and $25 \mathrm{mg} /$ $\mathrm{kg}$ of Cefazolin during the procedure. (Figures 6 and 7).

We aimed for the most central defect in most patients. We chose the device diameter to be at least $5 \mathrm{~mm}$ less than the total length of the long axis septal length to avoid possible trauma of the atrial roof. In the HELEX device group size was chosen to be 1.8 to two times the defect. The device position was evaluated by TEE or ICE to assess stability, residual shunt and possible encroachment on intracardiac structures. Once the position was deemed satisfactory the device was released.

After the procedure, two additional doses of antibiotics were given. Chest X-ray, ECG and TTE were performed the next day. Patients received low dose aspirin for 6 months. TTE was performed at follow up of 1, 6 and 12 months and then yearly. Residual shunt was graded as trivial if the jet width was $<1 \mathrm{~mm}$, small if the jet width was between $1-2$, moderate if $>2 \mathrm{~mm}$ and large if $>4 \mathrm{~mm}$.

\section{Results}

\section{Group A (Cribriform Device)}

There were 20 patients in this group (12 females and 8 males). The median age was 13 years (range 2.5- 66) and the median weight was $44 \mathrm{Kg}$ (range 13 -96). Of those 20 patients 12 were symptomatic (60\%) mainly with dyspnea on exertion. One patient had history of arrhythmias in the form of atrial fibrillation, two patients had previous TIA, one of them had CT brain changes and DVT and one patient had stroke. One patient had Down syndrome, one patient had Ehler Danlos syndrome, and one patient had mitral valve prolapse. Three patients had associated pulmonary stenosis, two of which had previous balloon dilation. Two patients had mild pulmonary hypertension $(\mathrm{PH})$ and normal PVR less than 4 woods units. The Down syndrome patient who was 7 years old with $\mathrm{PH} 3 / 4$ systemic with high PVR which dropped to 4 woods units in $100 \%$ oxygen with Qp/Qs of $1.5 / 1$, so he fulfilled the criteria for ASD closure. (Table 1).
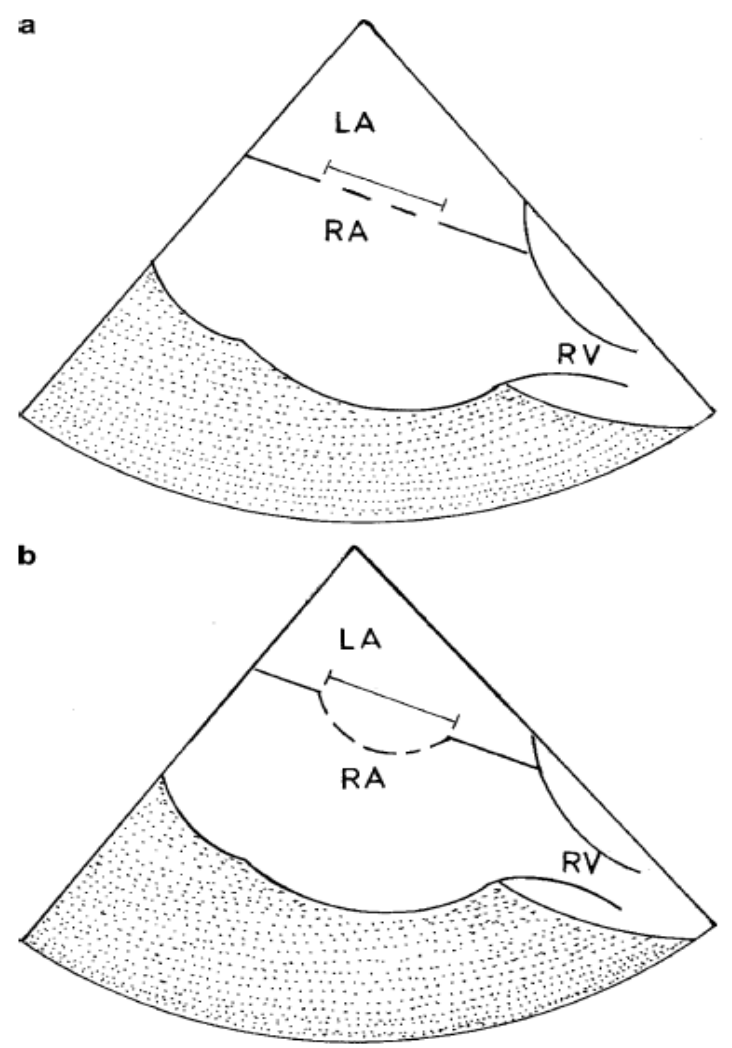

Figure 2. Method we used to measure the "unsteady atrial septum"
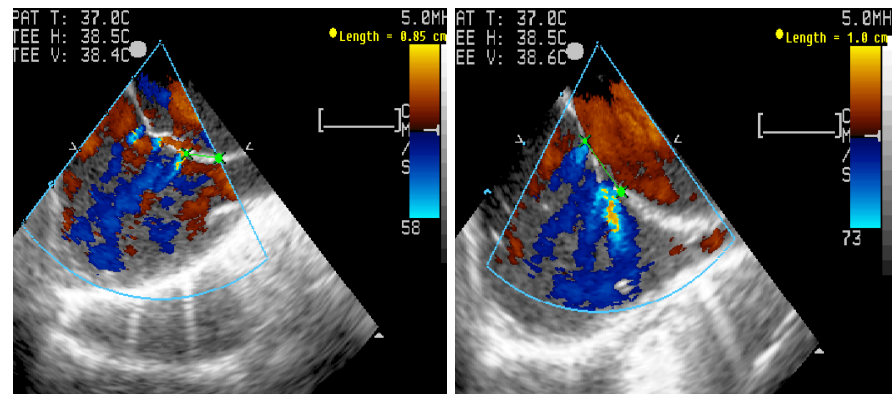

Figure 3. Multi fenestrated atrial septal defect in Bicaval and long axis views (TEE) 
Y1lmaz M (2018) An angiographic curiosity: Coronary artery ectasia. A review of possible aetiological factors, clinical and histopathological features and treatment

Table 1. Results

\begin{tabular}{|l|c|c|c|}
\hline & Group A (Cribriform) & Group B (HELEX) & 24 \\
\hline Number of cases & 20 & 15 years $(2.5-64)$ \\
\hline Median Age (range) & 13 years $(2.5-66)$ & $38 \mathrm{Kg}(12-98)$ \\
\hline Median Wt (range) & $44 \mathrm{Kg}(13-96)$ & $14 / 10$ \\
\hline Sex (F/M) & $12 / 8$ & $11 / 24(42 \%)$ \\
\hline Atrial Septal Aneurysm & $11 / 20(55 \%)$ & 3 \\
\hline Median number of fenestrations & 3 & $25 \mathrm{~mm}$ \\
\hline Mean device Size & $30 \mathrm{~mm}$ & $1.7 / 1 \pm 0.7$ \\
\hline Qp/Qs (mean \pm SD) & $1.47 / 1 \pm 0.3$ & $92 \pm 63 \mathrm{~min}$ \\
\hline Procedure Time \\
(mean \pm SD)
\end{tabular}

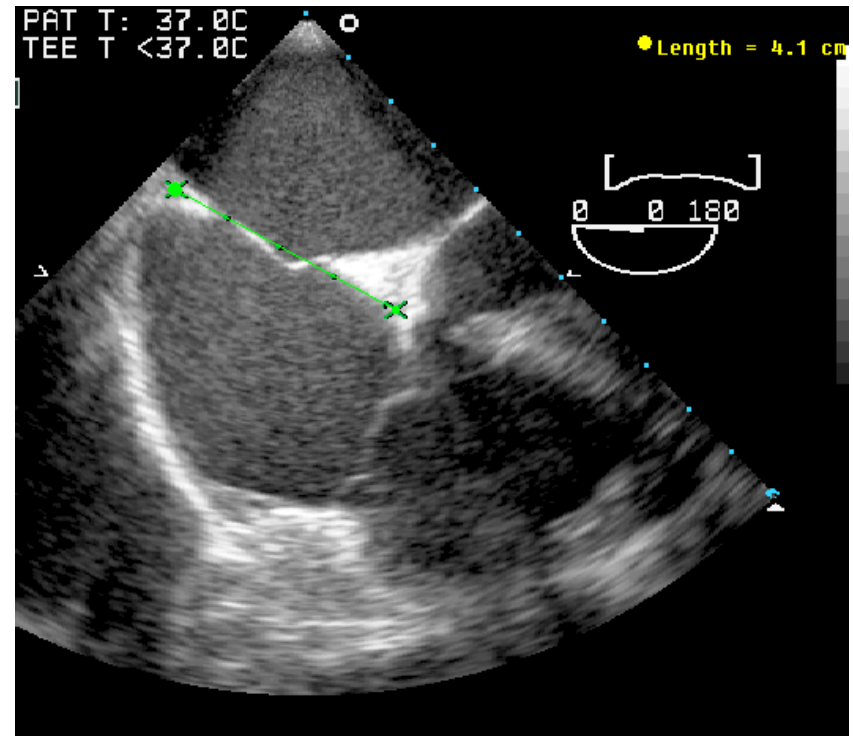

Figure 4. The maximum atrial diameter obtained prior to device size selection

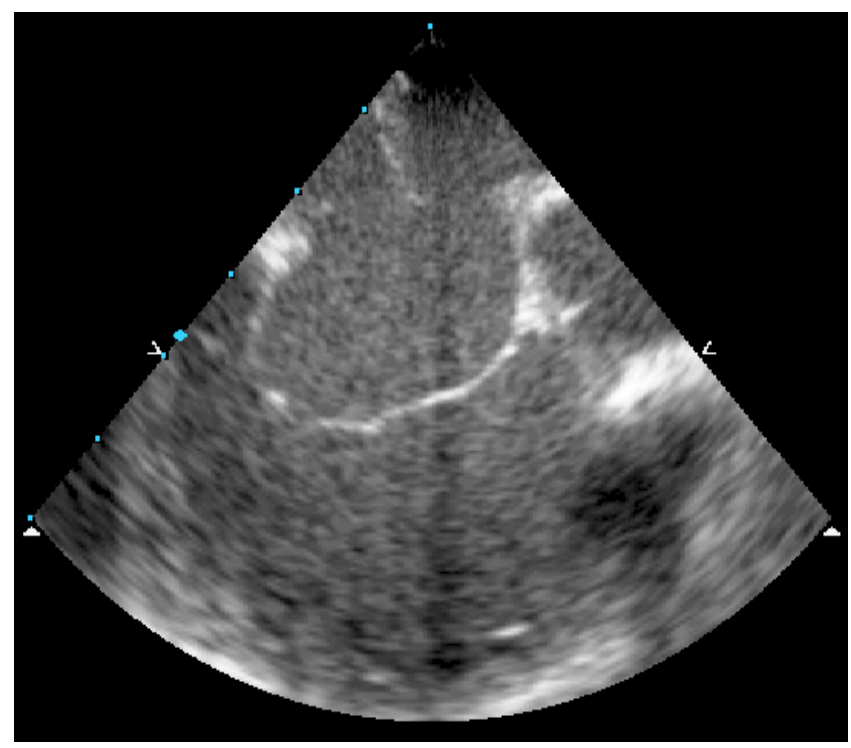

Figure 5. Atrial septal aneurysm with fenestrations

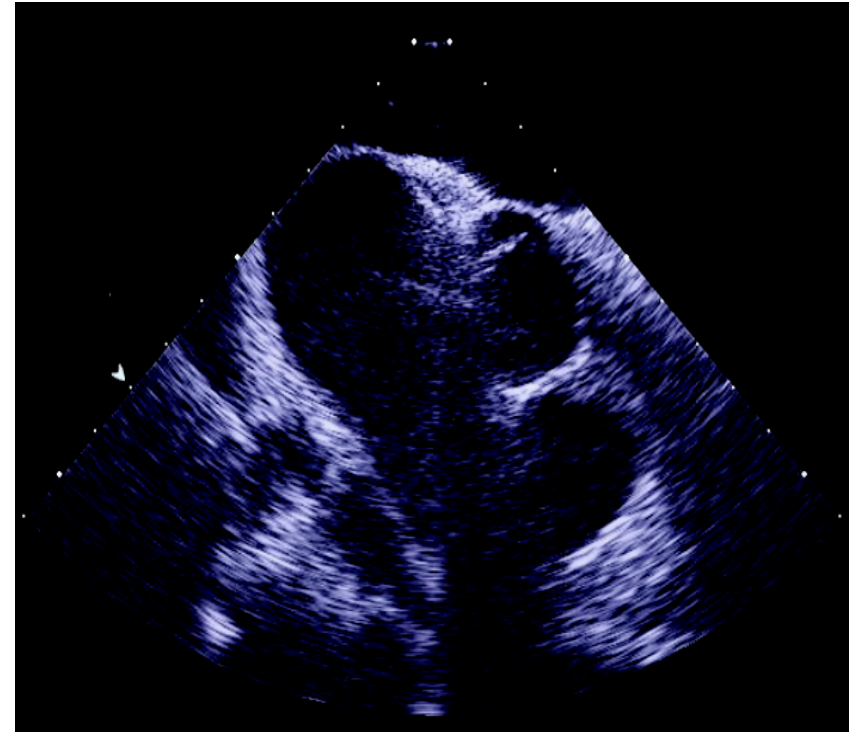

Figure 6. HELEX device in situ

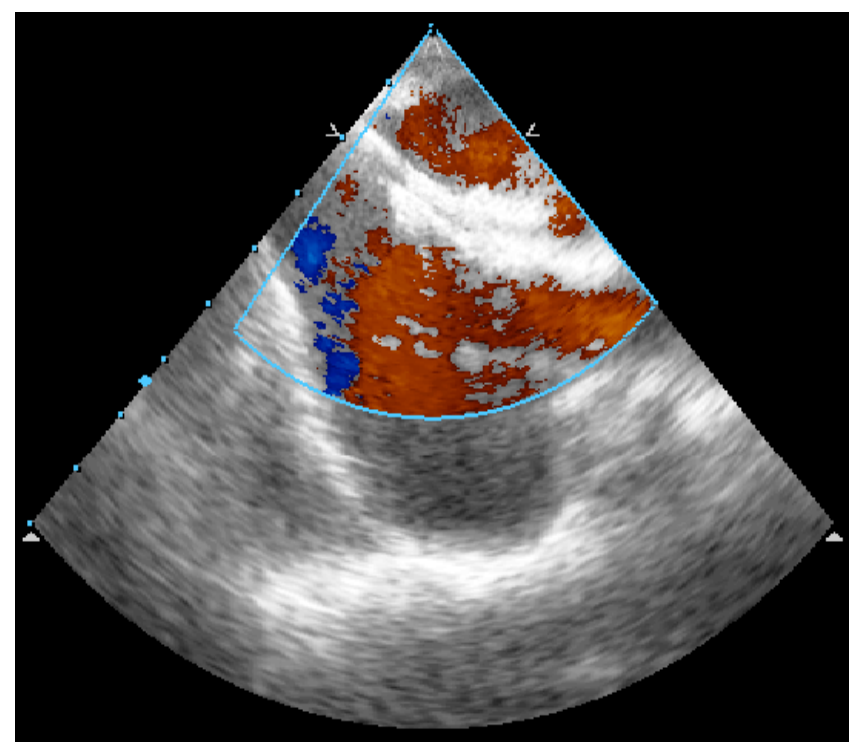

Figure 7. Cribriform device in Situ 
All the referrals were based on TTE findings of fenestrated defects and/or aneurismal AS. Eleven patients (55\%) had aneurismal AS. The number of defects was variable from 2 to 5 defects (median of 3 ). There were 9 patients who were found to have more defects by TEE than TTE. Seven patients had associated patent foramen ovale (PFO). ICE was used in the last 3 patients in this group. The mean procedure time was $68.7 \pm 29.5$ minutes and the mean fluoroscopy time $10.8 \pm 5.3$ minutes. The mean Qp:Qs was $1.47 / 1 \pm 0.3$.

\section{Follow Up}

Echocardiography was done in all patients with follow up range from 4 months to 4.5 years. There were 5 patients with next day residual leak that was small in 4 patients and moderate in 1 patient. These leaks disappeared on follow up in 3 patients. One case continues to have small leak after 4 years follow up and the second patient has been lost to follow up. This patient was a child who had 5 fenestrations with aneurysm and $25 \mathrm{~mm}$ device was used, which probably didn't cover all fenestrations.

\section{Complications}

One patient developed tachyarrhythmia during the procedure which reverted successfully with cardioversion. Late complications were: one patient developed first degree heart block and remained so over a three year follow up period. The Down syndrome patient developed progressive pulmonary hypertension over a follow up period of 4 years and was scheduled for surgical device removal. One patient with pre- procedure stroke continued to have repeated strokes despite an absence of any residual leak.

\section{Group B (HELEX device)}

There were 24 patients in this group. The median age was 11 years old (range 2.5 - 64) and the median weight was $38 \mathrm{Kg}(12-98 \mathrm{Kg}$ ). Of those 20 patients, 9 (40\%) were symptomatic 2 with breathlessness, 2 with failure to thrive and 3 patients had history of stroke, TIA and syncope. Two patients had Down syndrome, 2 patients had associated PDA and one had VSD which were all closed in the same procedure. One patient had mild Ebstein anomaly and another patient had previous balloon angioplasty of pulmonary stenosis. One patient had associated Wolf Parkinson White (WPW) and had ablation on the same procedure.

Like group A, patients were referred based on TTE diagnosis of fenestrated ASDs with and without aneurysm of the atrial septum. Eleven patients (45\%) had associated atrial aneurysm. Three patients had associated PFO. TEE was used as in group A to assess the defects in $17(85 \%)$ and ICE in 3 patients. The number of defects varied from 2 to 4 fenestrations. We used a guide wire to guide the catheter into the middle defect in 4 patients. The interatrial septal length was at least 10 $\mathrm{mm}$ longer than the selected device diameter.

The mean Qp:Qs was 1.7 \pm 0.7., the procedure time range (70-300 minutes) mean $92 \pm 63$ minutes and fluoroscopy time range (12-45 minutes) mean $21 \pm 9.7$ minutes. These times are exaggerated because simultaneous procedures were done in 4 patients (VSD and PDA device closure and Radiofrequency ablation).

Successful HELEX device implantation was achieved in 23 patients, one patient was switched to Cribriform ASD device $(35 \mathrm{~mm})$ after trial of two $20 \mathrm{~mm}$ Helex device but failed due to thick interatrial septum which deformed the device and prevented the system from locking.

\section{Follow Up}

Follow up echocardiography range from 6 month to 3 years. There was residual leak in 3 patients on echocardiographic examination the following day. This leak disappeared within a follow up period of two years in all patients. To our surprise, one patient redeveloped a small leak after complete closure one-year post procedure.

\section{Complications}

One patient had supraventricular tachycardia with hemodynamic compromise which was controlled by verapamil. On follow up TEE, one patient, it was noted that the inferior edge of both discs deviated to left atrium, however this was not causing any residual shunt, instability of the device nor encroachment on the aorta. This particular patient had a deficient aortic rim.

\section{Conclusion}

- Both devices are safe and effective in closure of multiple ASDs.

- HELEX devices had longer procedural and fluoro times but had less residual defects compared to Cribriform. Larger defects were closed by Cribriform more often than Helex devices

- The use of single device should replace the use of multiple devices to close multiple ASDs.

- The Helex device has an additional advantage that even at a late stage of delivery, if device removal is desired, traction on the retention suture unlocks the device and allows it to be withdrawn back into the delivery catheter.

\section{References}

1. Mügge A, Daniel WG, Angermann C, Spes C, Khandheria BK, et al. (1995) Atrial septa aneurysm in adult patients. A multicenter study using transthoracic and transesophageal echocardiography. Circulation 91: 2785-2792. [Crossref]

2. Awad S, Garay F, Cao QL, Hijazi Z (2007) Multiple Amplatzer Septal Occluder Devices for multiple atrial communications: Immediate and long term follow up results. Cath and Card Vasc Interv 70: 265-273. [Crossref]

3. Cao QL, Radtke W, Berger F, Zhu W, Hijazi Z (2000) Transcatheter closure of multiple atrial septal defects: Initial results and value of two- and three-dimensional transoesophageal echocardiography. Eur Heart J 21: 941-947. [Crossref]

4. Earing MG, Cabalka AK, Seward JB, Bruce CJ, Reeder GS, et al. (2004) Intracardiac echocardiographic during transcatheter device closure of atrial septal defect and patent foramen ovale. Mayo Clinic Proc 79: 24-34. [Crossref]

5. Numan M, El Sisi A, Tofeig M, Gendi S, Tohami T, et al. (2008) Cribriform amplatzer device closure of fenestrated atrial septal defects: feasibility and technical aspects. Pediatr Cardiol 29: 530-535. [Crossref]

Copyright: (C)2018 Y1lmaz M. This is an open-access article distributed under the terms of the Creative Commons Attribution License, which permits unrestricted use, distribution, and reproduction in any medium, provided the original author and source are credited. 